\title{
Revista Brasileira de Enfermagem REBEn \\ Formação docente e o ensino de Pós-Graduação em Saúde: uma experiência na UNIFESP
}

\author{
Teacher development and Post-Graduate studies in Health: an experience at the Federal \\ University of São Paulo
}

\author{
Formación docente y enseñanza de Postgrado en Salud: una experiencia en la \\ UNIFESP
}

\section{Maria Aparecida de Oliveira Freitas}

Mestre em Ensino em Ciências da Saúde. Pedagoga da Universidade Federal de São

Paulo, SP.

cida@proex.epm.br

Otília Maria Lúcia Barbosa Seiffert

Professora Doutora em Psicologia. Professora do Programa de Mestrado Ensino em Ciências da Saúde da UNIFESP, São

Paulo, SP.

$\underline{\text { o.seiffe@unifesp.br }}$

Parte da Tese de Mestrado apresentada à Universidade Federal de São Paulo no ano de 2005, para obtenção do título de Mestre.

Créditos do Trabalho ao Centro de Desenvolvimento do Ensino Superior em Saúde - CEDESS da UNIFESP.

\section{RESUMO}

O artigo trata do significado atribuído à Disciplina de Formação Didático-Pedagógica em Saúde por egressos, nos Programas de Pós-Graduação Stricto Sensu da UNIFESP. O percurso metodológico compreendeu pesquisa bibliográfica sobre docência universitária; pesquisa documental à legislação nacional sobre ensino superior, docência e pós-graduação, e documentos relacionados à Disciplina; mapeamento dos egressos no período de 1998 a 2003, para composição da amostra dos sujeitos que estivessem exercendo a docência; aplicação de questionário semi-estruturado a 112 egressos e análise dos dados orientada pela técnica de análise de conteúdo. Os resultados revelam influência da Disciplina na atuação da docência desses egressos, indicando sua importância para o processo de formação docente para o magistério superior em saúde.

Descritores: Docentes; Centros educacionais de áreas de saúde; Educação de pós-graduação.

\section{ABSTRACT}

The aim of this study was to analyze the views and conceptions shared by the graduate students who attended the Pedagogy and Didactics in Health Sciences Course, offered by the Graduate Programs at the UNIFESP. The methodological approach consisted of bibliographic research on the higher education teaching; documental analysis involving the national legislation for higher education, teaching and graduate studies and documents related to this Course. Graduate students from 1998 and 2003 were mapped in order to build the samples of those (112 egresses) that were involved in teaching activities. The data were collected through a semi-structured questionnaire. The data analysis, oriented by the Content Analysis Technique, reveals that this experience has an influence on the way these professors understand and practice their teaching skills, showing the importance for the faculty development at the higher education level in Health Sciences.

Descriptors: Faculty; Area health education centers; Education, graduate.

\section{RESUMEN}

El artículo trata del significado atribuido a la Disciplina de Formación Didáctico-Pedagógica en Salud por alumnos que cursaron esa disciplina. Esta materia es ofrecida en los Programas de Postgrado de la UNIFESP. El camino metodológico comprendió pesquisa bibliográfica sobre docencia universitaria; pesquisa documental consultas a la legislación nacional sobre enseñanza superior, docencia, postgrado y documentos relacionados a la Disciplina; El relevamiento de los egresados en el período 1998-2003 fue necesario para componer la muestra de los sujetos que ejercieron la docencia (112 egresados) a los cuales se aplicó un cuestionario semi-estructurado. El análisis de los datos, realizado por análisis de contenido, muestra que la Disciplina influenció eses sujetos que actúan en la docencia, indicando su importancia en el proceso de formación docente para el magisterio superior en salud. Descriptores: Docentes; Centros educacionales de área de salud; Educación de postgrado.

Freitas MAO, Seiffert OMLB. Formação docente e o ensino de Pós-Graduação em Saúde: uma experiência na UNIFESP. Enferm. Rev Bras Enferm 2007 nov-dez; 60(6): 635-40.

\section{INTRODUÇÃo}

O propósito deste artigo é apresentar resultados da pesquisa que tomou como objeto de estudo a experiência de formação docente no âmbito dos programas de pós-graduação stricto sensu na Universidade Federal de São Paulo - UNIFESP: a Disciplina de Formação Didático-Pedagógica em Saúde.

Algumas preocupações mobilizaram a realização desta pesquisa, dentre essas o reconhecimento que, ainda nos dias de hoje, muitos docentes universitários não receberam formação inicial ou continuada para o exercício desta atividade, prevalecendo a cultura de que basta o conhecimento e domínio de determinado 
campo do saber para tornar-se professor. Ao lado disso, debates e estudos mostram a necessidade de se instituir na educação superior, processos ativos de aprendizagem, que fomentem a autonomia, criatividade e criticidade dos educandos. Nessa direção demanda-se a consolidação de espaços de formação que favoreçam futuras aprendizagens e o enfrentamento de problemas e desafios no âmbito do exercício profissional. A concretização desse desafio exige tomar como foco de reflexão e problematização o trabalho docente com a perspectiva de qualificar a formação profissional de nível superior.

A aproximação ao objeto deste estudo nos remeteu à política de pósgraduação stricto sensu no País, em especial ao Parecer n 977 de 03/12/ 1965 (1), que definiu o modelo de pós-graduação no Brasil, organizando-se para formar professores de nível superior e pesquisadores, e aos Planos Nacionais de Pós-Graduação(2), que assumem os objetivos de fomentar um sistema de formação de qualidade, consolidar a pesquisa e fortalecer 0 ensino de pós-graduação também como espaço de formação docente. Acrescenta-se, ainda, a Nova Lei de Diretrizes e Bases da Educação(3), aprovada em 20/12/1996, que delega à pós-graduação a preparação de docentes para o exercício do magistério superior, prioritariamente em programas de mestrado e doutorado. Estabelece ainda, que pelo menos um terço do corpo docente das universidades seja titulado em programas de pósgraduação stricto sensu, fortalecendo esse nível de ensino como espaço para a formação docente.

Essas diretrizes nacionais se entrelaçam com diversos caminhos que têm emergido para a profissionalização da docência do magistério superior. Na área da saúde, evidencia-se um esforço de alguns programas de pósgraduação em Enfermagem, Medicina e Odontologia em incluírem na proposta curricular disciplinas de Metodologia do Ensino Superior ou Didática.

Em se tratando daárea de Enfermagem, cabe ressaltar que na graduação, os futuros Enfermeiros têm a oportunidade, em seu processo de formação, de realizar estudos no campo da Pedagogia. A Resolução CNE/CES No $3^{(4)}$, de 7 de novembro de 2001, que institui as Diretrizes Curriculares Nacionais dos Cursos de Graduação em Enfermagem, prevê em seu Artigo $6^{\circ}$ inciso III, alínea "d" conteúdos pertinentes à capacitação Pedagógica do Enfermeiro, que lhe dará suporte para planejar, implementar e participar de forma ativa na formação de outros profissionais, e em programas de educação e promoção à saúde.

Nessa direção, a UNIFESP fundada com o objetivo de criar um espaço específico para a formação docente nos cursos de pós-graduação, regulamentou a obrigatoriedade da disciplina Pedagogia Médica e Didática Especial, em 1988, nos programas de mestrado e doutorado da área médica. Em 1996, essa disciplina foi reestruturada, com a nominação de Formação Didático-Pedagógica em Saúde, tornando-se obrigatória a todos os programas de mestrado e doutorado, cuja coordenação e desenvolvimento, são de responsabilidade do Centro de Desenvolvimento do Ensino Superior em Saúde - CEDESS.

O significado e a importância dessa disciplina na estrutura da pósgraduação da Instituição têm fomentado reflexões, debates e estudos de pesquisadores do CEDESS . O principal estudo desenvolvido revela que

${ }^{a}$ Fundada em 1933, Escola Paulista de Medicina/EPM transformou-se na Universidade Federal de São Paulo/UNIFESP em 1994, sendo a primeira universidade especializada na área da Saúde no Brasil. A partir de 2006 amplia sua atuação para outras áreas do conhecimento. Atualmente oferece os seguintes cursos de graduação: Campus São Paulo: Medicina, Enfermagem, Tecnologia Oftálmica, Fonoaudiologia e Ciências Biológicas - Modalidade Médica: Campus baixada Santista (partir de 2006):Psicologia, Nutrição, Educação Física, Terapia Ocupacional e Fisioterapia; Guarulhos/SP (a partir de 2007): Filosofia, Historia, Pedagogia e Ciências Sociais.

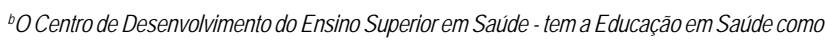
área privilegiada do conhecimento para o desenvolvimento das atividades de ensino, pesquisa e extensão. Em setembro de 2003, este Centro iniciou o Mestrado Ensino em Ciências da Saúde, tendo como linhas de pesquisa Currículo, Aprendizagem e Avaliação. os pós-graduandos declararam ter uma visão mais abrangente da prática docente no ensino superior na área da saúde a partir dessa experiência de formação( ${ }^{(5)}$. Entretanto, muitas são as inquietações que ainda permeiam essa atividade, o que a torna pertinente como objeto de investigação.

\section{OBJETIVO}

Analisar o significado atribuído por egressos à Disciplina de Formação Didático-Pedagógica em Saúde, oferecida nos programas de Pós-Graduação Stricto Sensu da UNIFESP, identificando sua importância para o magistério superior na área da saúde, no período de 1998 a 2003.

\section{O PERCURSO METODOLÓGICO}

Após a aprovação do Projeto pelo Comitê de Ética em Pesquisa da UNIFESP, a construção desta pesquisa realizou-se a partir de procedimentos distintos, porém interligados. A pesquisa bibliográfica, envolvendo estudos acerca da docência na educação superior. A pesquisa documental, abrangendo consulta e análise da legislação sobre ensino superior, docência e pósgraduação, e documentos relacionados à Disciplina de Formação DidáticoPedagógica em Saúde. A pesquisa empírica de campo, numa fase inicial, compreendeu um mapeamento dos 2.496 alunos que freqüentaram a disciplina no período de 1998 a 2003, cujas informações foram coletadas junto à Secretaria do CEDESS: nome dos alunos-egressos, endereço, telefone e exercício da docência ou não - informação primordial para a definição dos participantes da pesquisa. Aausência de informações relativas ao ano de 1999 inviabilizou contato com egressos desse ano. A amostra congregou um grupo de alunos que havia concluído o mestrado ou doutorado e indicaram a disponibilidade em participar da pesquisa. Num universo de 322 mestres e doutores identificados como docentes, a amostra compreendeu 112 sujeitos, residentes em diferentes cidades do território nacional, para os quais o Questionário e o Termo de Consentimento Livre e Esclarecido foram encaminhados via correio, acompanhados de envelope selado e endereçado para devolução. O retorno obtido foi de $35 \%$, compatível com as indicações na literatura, assim distribuídos: 7,1\%, referentes a 1998, 4,5\% a 2000, 2,7\% a 2001, 9\% a 2002 e $11,7 \%$ a 2003.

Esse questionário semi-estruturado e pré-testado foi organizado a partir dos seguintes eixos temáticos: a Disciplina de Formação Didático-Pedagógica em Saúde; a Docência de Ensino Superior em Saúde; Papel do Docente na Formação do Aluno de nível Superior; Concepções de Ensinar, Aprender e Avaliação, Práticas Avaliativas; Planejamento e as Técnicas de Ensino; Relação Professor-Aluno; Formação Docente; Desafios na/da Docência; e Contribuições da Disciplina, além de Pontos Positivos e Negativos.

O tratamento dos dados compreendeu uma sistematização quantitativa para caracterização dos sujeitos da pesquisa e uma análise qualitativa ${ }^{(6)}$ das respostas livres envolvendo as seguintes etapas: leitura seletiva de todo 0 material; redimensionamento dos eixos temáticos a partir dos depoimentose do roteiro do questionário; escolha dos depoimentos correspondentes a cada eixo temático e análise-descritiva dos dados agrupados.

Os depoimentos dos egressos estão identificados pela letra $D$, seguida do número de ordem da devolução dos questionários - D1; D3; D6; D8; D10; D13; D14; D15; D16; D17; D20; D25; D26; D34; D37; D38 e D39. Neste artigo, estão transcritos depoimentos que se revelaram capazes de indicar posições representativas do grupo de docentes participantes da pesquisa, permitindo não apenas apreender significados atribuídos à disciplina, mas também fragmentos do fazer docente que retratam o cotidiano do ensino de graduação em Ciências da Saúde no país.

\section{REVISÃO DA LITERATURA}

A docência para o ensino superior em saúde: alguns apontamentos Os constantes e importantes debates e estudos sobre a docência para 0 
ensino superior, particularmente sua formação, sejam no âmbito nacional ou internacional, têm em comum a premissa de que não basta ter o domínio de conteúdo específico para saber ensiná-lo. Ser professor demanda ir muito além das características historicamente consolidados por um ensino tecnicista e pela exclusiva transmissão de conhecimentos É necessário que o professor tenha formação científica, pedagógica, prática, técnica e política, desenvolvendo assim, as competências profissionais de um educador ${ }^{(7-9)}$.

A literatura revisada indica que na área da saúde, a docência deve incluir, além das competências técnico-científicas, a competência didático-pedagógica parafavorecer o desenvolvimento qualitativo do processo ensino-aprendizagem. A competência organizativa também deve fazer parte da prática docente, pois as ações pedagógicas inerentes à formação de quem aprende exigem 0 domínio técnico, político e científico sobre planejamento, organização, controle e avaliação ${ }^{(8 ; 9)}$. Deve-se também, privilegiar uma formação que estimule a perspectiva crítico-reflexiva do professor, geradora de pensamento autônomo e da auto-formação participativa. Nessa direção, intenciona-se, formar o professor capaz de refletir na e sobre a ação, implicando um compromisso não apenas do docente, mas também da instituição escolar ${ }^{(10-12)}$,

Ao lado disso, a formação continuada de professores deve ser assumida pelas instituições e seus docentes como espaço para a reflexão crítica da prática e promoção de relevantes transformações no cotidiano acadêmico. Tomar a ação docente como ponto de partida para a reflexão, propiciará a compreensão de seus significados e conseqüências, permitindo encontrar soluções para aperfeiçoá-la ${ }^{(13)}$. Desta perspectiva, reconhecemos a necessidade das instituições de ensino superior favorecer a criação de espaços para discussões sobre a qualidade da docência, e seus desdobramentos nos processos de formação profissional. Assim, abrem-se oportunidades para se criar caminhos para que a docência deixe de ser vista apenas como mais uma opção de trabalho, sem pré-requisitos pedagógicos específicos e passe a ser profissionalizada, contribuindo e gerando as mudanças desejadas que tanto discutimos no âmbito do ensino de graduação.

\section{RESULTADOS E DISCUSSÃO}

\subsection{Participantes da Pesquisa}

O grupo de egressos participantes da pesquisa apresentou o seguinte perfil: $61,5 \%$ eram do gênero feminino e $38,5 \%$ do masculino; $20,5 \%$ docentes dos cursos de Odontologia, 12,8\% de Enfermagem e 17,9\% de Medicina; $71,8 \%$ portadores do título de Mestrado, 10,3\% de Doutorado e $17,9 \%$ de Mestrado e Doutorado. 74,4\% exercem a docência em apenas uma instituição de ensino; $23 \%$ em duas instituições e 2,6\% em três instituições, sendo 66,7\% em Instituições privadas. Aamostra, cuja variação do tempo de exercício da docência é de um ano a trinta anos, tinha a seguinte configuração: 25,6\% da Enfermagem; 25,6\% da Medicina; 20,6\% da Odontologia e 20,5\%) da Fisioterapia.

\subsection{A disciplina de Formação Didático-Pedagógica em Saúde}

Esta disciplina tem uma carga horária de 60 horas, distribuídas em dez encontros de três horas cada um, e 30 horas de atividades extra classe. Ao orientar-se pelo pressuposto que "o preparo docente não significa apenas instrumentação técnica, mas também uma reflexão desta prática e da realidade onde esta se realiza ${ }^{(5) "}$, assume como objetivo central preparar o pósgraduando para o exercício da função docente em cursos de graduação em Saúde. Tal proposta é desenvolvida por um corpo docente multiprofissional, incluindo profissionais das áreas de Medicina, Psicologia, Pedagogia e Biologia.

\subsubsection{Os Núcleos Temáticos}

Com o propósito de favorecer aos pós-graduandos uma formação crítica da docência no ensino superior, principalmente na área da Saúde, a disciplina privilegia Núcleos Temáticos como: as políticas para a educação superior brasileira; fundamentos epistemológicos da formação do profissional em saúde; docência em saúde; planejamento de ensino; o processo de ensinar e aprender e as principais tendências pedagógicas; técnicas de ensino; comunicação e recursos didáticos; currículo e a avaliação educacional.

\subsubsection{Dinâmica de Trabalho}

A dinâmica de trabalho compreende três momentos distintos, mas que se retroalimentam continuamente: discussão e construção coletiva de reflexões teóricas sobre os temas privilegiados e respectivas bibliografias; o planejamento de uma atividade de ensino, observando os princípios e fundamentos da construção de um plano pedagógico; e a prática de ensino, desenvolvida da perspectiva de diferentes técnicas e recursos didáticos.

\subsection{A formação docente na óptica de alunos egressos}

A análise dos registros escritos acerca da disciplina de Formação DidáticoPedagógica em Saúde favoreceu apreender fragmentos do cotidiano da prática docente dos egressos e a importância atribuída a essa Disciplina no processo de formação na pós-graduação stricto sensu.

\subsubsection{Recordações da Disciplina de Formação Didático-Pedagógica em Saúde}

Quando indagados sobre a disciplina, 100\% lembraram tê-la cursado e indicaram a importância dessa experiência para suas práticas docentes. Os registros mostram uma articulação com eixos teórico-metodológicos que têm fundamentado o desenvolvimento desse processo de formação - "Em minha opinião, foi a melhor disciplina cursada; ajudou bastante na formulação das aulas, assim como na avaliação dos alunos. Eram aulas descontraídas, com bastante debate" (D1).

Em se tratando dos conteúdos e práticas que mais marcaram essa experiência, as respostas foram variadas, salientando-se a metodologia de ensino-aprendizagem adotada pelos professores

Na disciplina tive a oportunidade de aprender como o professor pode tirar de si a responsabilidade de ser o centro da aula. Com isso, ficou muito claro que o professor deve ser o coordenador do processo ensinoaprendizagem, proporcionando aos alunos formas de chegar ou obter o conhecimento (D6).

\subsubsection{A docência de ensino superior em saúde e seus desafios}

Os problemas e desafios que dizem respeito ao processo ensinoaprendizagem, para os egressos abrangem principalmente o despreparo ea falta de maturidade dos alunos que chegam à universidade.

"Alunos cada vez mais desinteressados na sua futura profissão (D1)".

Para lidar com essas situações, os professores procuram dinamizar as aulas para despertar o interesse dos alunos:

"Tento preparar aulas mais chamativas; cobro mais reflexão em sala e na prova (D1)".

É interessante notar o foco dado aos alunos e a ausência de questionamentos sobre a própria prática docente e o contexto institucional e/ ou político.

Perguntados se tivessem a oportunidade de orientar um ingressante à docência no ensino superior em cursos de ciências da saúde, os egressos apontaram como indispensável à formação didático-pedagógica e o contato com estudos e pesquisas na área:

"Recomendaria se qualificar e realizar cursos de didática (D14)".

Apreendemos, assim, que a formação didático-pedagógica facilita o planejamento das atividades e favorece 0 acesso a práticas inovadoras no 
processo ensino-aprendizagem, na tentativa de tornar esse momento estimulante para os alunos e prazeroso para o professor.

\subsubsection{Papel do docente na formação do aluno de nível superior}

Ser um facilitador na busca de informação é a percepção que os egressos têm sobre o papel do docente na formação do aluno de nível superior. Ressaltam que o professor deve agir como mediador no processo de formação dos indivíduos, no sentido de preparar profissionais críticos e competentes:

"Direcionar o aprendizado, explicando os pontos principais de cada fase (D8)"

\section{"Colaborar para a construção do conhecimento do aluno (D16)".}

O professor é fundamental na vida dos alunos como elemento facilitador, orientador e incentivador da aprendizagem. Não é possível, diante dos desafios que surgem no exercício da docência, ser tão somente repassador de conhecimentos, pois este papel está em crise há algum tempo, e mais, completamente ultrapassado. Afirmam ainda que

O docente tem o papel de colaborar na formação técnica associada à visão crítica do profissional. Ele também participa da transformação, da busca de novos conhecimentos e da formação do aluno enquanto ser humano: responsabilidade, solidariedade e compromisso (D37).

A preocupação com a formação de profissionais críticos-reflexivos, comprometidos com a sociedade para a qual estão sendo formados, é mais uma dimensão dos estudos desenvolvidos na disciplina em foco, onde a reflexão crítica é assumida como fundamental para a formação de nível superior. Esta intencionalidade projeta o papel significativo do profissionalismo docente e sua responsabilidade diante dos atuais desafios e demandas à qualificação de cursos de graduação das Ciências da Saúde.

\subsubsection{Concepções de ensinar e aprender}

Os conceitos de ensinar e aprender apreendidos indicam pressupostos diferenciados. Há a compreensão de que o ato de ensinar deve ser uma construção de conhecimento, troca e transformação de conteúdo, sinalizando, mais uma vez, uma convergência com a Disciplina:

"Construir conhecimento de forma contínua e dinâmica, através da troca de informações, estimulando o raciocínio do aluno (D13)".

Entretanto, alguns ainda acreditam que ensinar deve ter o objetivo de:

"Transmitir conhecimento (D20)".

A aula é considerada local privilegiado para que o professor passe 0 conteúdo, cabendo ao aluno memorizá-lo e reproduzi-lo nas provas. Desta maneira, temos aí somente a transmissão da informação como ensino e 0 professor fica como fonte do saber, tornando-se o portador e a garantia da verdade. Quanto ao conceito de aprender, alguns entendem como modificação de comportamento e outros como assimilação de novos conceitos e conhecimento:

"De uma maneira geral, aprender é captar ou demonstrar que o conteúdo ensinado foi capaz de modificar um comportamento(D 14)".

Aprender implica "assimilar novos conceitos e aprimorar os conceitos já existentes (D17)".

"A aprendizagem universitária pressupõe, por parte do aluno, aquisição e domínio de um conjunto de conhecimentos, métodos e técnicas científicas de forma crítica ${ }^{(14) "}$. Os depoimentos sinalizam essa evidência:

"Dar significado a algo conhecido; Incorporar conceitos, refletir e construir novas idéias (D17)".

A importância de o professor colaborar para o crescimento intelectual do aluno, a partir dos conhecimentos prévios, para (re) construir novas idéias, dando significado a algo que já existe em sua estrutura cognitiva e sedimentando os conceitos existentes, são premissas reconhecidas pelos participantes da pesquisa.

\subsubsection{Concepções e práticas de avaliação}

Estaé mais uma dimensão que revela o fazer docente, consequentemente, constitui-se um campo de grande relevância no processo de formação de professores. Um número expressivo de egressos percebe a avaliação como um processo realizado ao longo da trajetória do aluno, indicando uma visão sóci-construtivista do processo de avaliação, revelando uma conectividade com a abordagem teórica trabalhada na Disciplina

A avaliação é uma parte do processo ensino-aprendizagem, não um ponto final deste processo. Deve ser contínua e servir para indicar pontos que devem ser reforçados ao longo do período (D6).

Contudo, alguns expressam conceitos tradicionais, considerando a avaliação um julgamento definitivo do aluno:

\section{"Medir o conhecimento aprendido (D26)".}

Dentre os instrumentos de avaliação privilegiados pelos professores, destaca-se a prova dissertativa - 82\% utilizam-na para avaliação do conhecimento. As provas de múltipla escolha, seminários e pesquisas aparecem como instrumentos preferenciais de avaliação, além de trabalhos práticos em clínicas e laboratórios, observação do atendimento à pacientes, prova prática, trabalho individual, caso prático com análise teórica, prática de laboratório, portfólio e avaliação da prática de estágios supervisionados. Para esses egressos, a definição sobre como avaliar tem sido determinada por alguns fatores:

\section{"Número de alunos em sala de aula; tempo disponível (D10)".}

Há uma predominância da avaliação quantitativa por imposição de algumas instituições, deixando os professores sem opção para uma avaliação formativa do aluno:

"Infelizmente a instituição nos obriga a apresentar um critério único seguindo resoluções pré-estabelecidas por algum Comitê Interno da própria instituição (D20)".

Contudo, vários professores desenvolvem esforços para proceder a uma avaliação formativa dos alunos, indicando a Disciplina como referencial importante para essas práticas. Estes e outros depoimentos nos fazem refletir sobre possíveis fatores que influenciam determinada prática docente. Afinal, as ações pedagógicas trazem marcas e ecos de relações que se estabelecem entre o indivíduo, o social e o institucional.

\subsubsection{O planejamento de ensino}

Assumindo que planejar é uma atividade que faz parte do ser humano, $e$ componente fundamental da ação educacional, o professor não pode deixar de realizá-lo para a organização do processo de ensino-aprendizagem a ser construído. Saber planejar, estabelecer objetivos, definir conteúdos, métodos de ensino e da aprendizagem, são competências fundamentais ao trabalho docente. Tal exigência é um dos pilares da Disciplina, construído pela discussão teórica e pelo exercício de planejamento de uma atividade de ensino. 
Os participantes da pesquisa ressaltam a importância desse eixo temático, salientando que 0 ato de planejar constitui-se também um guia de estudo do tema para o próprio professor quando decide acerca dos objetivos de aprendizagem, das metodologias de ensino e recursos didáticos

Primeiro considero o tempo disponível, estabeleço objetivos, introduzo o tema provocando discussão em torno do mesmo, abro espaço para discussões mais aprofundadas, ofereço material para leitura, ou sugiro textos, apresento questões pertinentes ao tema, e faço a conclusão (D3).

\subsubsection{As técnicas de ensino e a relação professor-aluno}

As técnicas de ensino no cotidiano da sala de aula constituem mediações na relação professor-aluno-conhecimento, favorecendo situações de aprendizagem e possibilitando 0 crescimento do aluno em diferentes dimensões da formação acadêmica. Os professores têm empregado variadas técnicas de ensino: $74,3 \%$ utilizam-se de aulas práticas devido a natureza dos cursos da área da saúde; aulas expositivas dialogadas (69,2\%); seminários (53,8\%); aula expositiva (51,2\%); aula demonstrativa (43,6\%); discussão e debates (41\%); problematização (30,8\%); estudo dirigido (28,2\%); estudo de texto (28,2\%); oficina de trabalho (12,8\%); PBL $(7,7 \%)$ e aula com pôster $(7,7 \%)$.

Estudos sobre a prática docente no ensino superior na área da Saúde têm mostrado que existem dois grandes modelos: as aulas teóricas e aulas práticas, sendo estas ministradas nos mais diferentes ambientes tais como laboratórios, ambulatórios, hospitais e Unidade Básica de Saúde, que podem abrigar estágios e atividades práticas ${ }^{(15)}$.

Nos cursos da área da saúde, a diversidade de técnicas de ensino permite ao professor planejar suas aulas de forma criativa, fugindo dos modelos tradicionais centrados no professor, e permitindo ao aluno vivenciar práticas que o torne construtor autônomo e criativo de conhecimentos.

\subsubsection{Formação docente}

As competências indicadas à docência na área da saúde dizem respeito aos domínios científico, técnico e pedagógico ${ }^{(17)}$, confirmado pelos participantes da pesquisa:

Desenvolver diferentes técnicas didáticas, oferecendo aos estudantes inúmeras opções para que o mesmo possa optar por aquela que melhor se adapte. Oferecer condições de utilizar todas as técnicas de ensino (PBL e tradicional) para que o professor possa utilizá-las em sua prática diária (D39).

A formação inicial e continuada de professores auxilia o professor no exercício de sua profissão, pois não basta sua vontade em investir nessa formação, as instituições de ensino devem possibilitar que esta prática se concretize $^{(11)}$. Entretanto, 74\% dos egressos indicaram que nas instituições onde trabalham não há qualquer política de investimento na formação docente:

\section{"A faculdade onde leciono não consideraisso importante, infelizmente(D25)".}

E, ainda, $61,5 \%$ das Instituições não oportunizam a participação dos professores em programas de formação/capacitação docente, evidenciando ainda o não reconhecimento da docência como profissão. Somente $25,7 \%$ dos professores disseram participar desse tipo de atividade que, às vezes, são oferecidas por pedagogos em esporádicas reuniões didático-pedagógicas com professores e coordenadores:

"No início de ano letivo a faculdade prepara uma semana de atividades para os docentes, que vai desde discussão de técnicas atuais até a preparação do plano de ensino (D15)".

Em 35,9\% das instituições, as quais os egressos estão vinculados, registra-se demanda ou favorecimento de atividades de formação/capacitação docente, sinalizando passos importantes ao processo de qualificação da educação superior.

\subsubsection{Contribuições da Disciplina}

O conhecimento pedagógico é essencial para o bom desempenho da função docente. 0 domínio de técnicas, novas metodologias e um novo conceito de avaliação contribuem para melhor desempenho da função $0^{(5 ; 7-9)}$. Os egressos revelaram compreensão da importância da formação pedagógica para o exercício da docência, de novas estratégias e metodologias para ensinar, liberdade de expressão e o conhecimento de novas práticas de avaliação:

"Aprendizagem de novas estratégias e métodos de ensinar; autopercepção de estilo docente, métodos de avaliação (D34)".

Considerando a obrigatoriedade da disciplina no currículo da pós-graduação da UNIFESP, solicitamos que apresentassem sua opinião sobre esse requisito. A grande maioria aponta sua a relevância para a formação ao magistério superior e entende que deve continuar sendo obrigatória.

Acho muito válida e importante, pois a formação do professor universitário foi e é sempre muito empírica nas universidades, sendo preconizada apenas a habilidade profissional, e o que vemos em muitas universidades e no meu curso também, é a má formação didática do professor (D16).

Em se tratando de pontos positivos da Disciplina, os egressos destacaram: dinâmica de desenvolvimento da disciplina; a oportunidade para aprendizado de novas técnicas de ensino e de avaliação; a importância de estudos sobre o processo ensino-aprendizagem e o planejamento de ensino:

"Diferentes tipos de planejamento (D8);

"Diferentes tipos de aula ministrada pelos pós-graduandos, convívio e troca de experiências (D38)".

Quanto a aspectos indicaram a pouca carga horária, considerada insuficiente para 0 aprofundamento dos temas abordados e a prática de ensino. Isto nos permite identificar uma necessidade dos egressos em aprofundar estudos sobre docência e temas afins:

"A disciplina poderia ser mais extensa; poderia durar mais tempo (D16)".

\section{CONSIDERAÇÕES FINAIS}

No resgate da experiência de formação docente nos programas de pósgraduação stricto sensu, a partir de olhares de egressos-docentes, podemos constatar que a UNIFESP consolida uma importante iniciativa de profissionalização docente, fundamental ao professor do ensino superior. A disciplina Formação-Didático Pedagógica em Saúde possibilita crescimento pedagógico e reconstrução da prática educativa, sinalizando novas formas de vivenciar o trabalho docente, embora se evidencie que uma única experiência não é suficiente para formar professor. Entretanto, deixa algumas marcas e ecos.

Esta experiência da UNIFESP sinaliza o quanto é viável e necessário criar nas Instituições de Ensino Superior, espaços para reflexões sobre a educação superior e desenvolvimento profissional, procurando abandonar 0 tratamento meramente burocrático do trabalho docente. Os depoimentos analisados sinalizam o quanto isso é viável e necessário, e como essa experiência de formação docente nos programas de pós-graduação stricto sensu constitui-se importante espaço de aprendizagem no qual pósgraduandos-docentes têm a oportunidade de refletir sobre suas práticas, 
contribuindo para que seus alunos deixem de assistir aula, para aprender a fazer aula. Assim, têm a oportunidade de exercitar a construção do conhecimento, tendo no professor um colaborador e mediador desse processo. Investir na criação desses espaços de formação docente poderá gerar mudanças importantes na qualidade do ensino, uma vez que busca a preparação política, científica e pedagógica de professores para o magistério do ensino superior possibilitando ainda, a revisão da prática daqueles que já são professores.

\section{REFERÊNCIAS}

1. Brasil. Parecer $n^{0} 977$ de 03 de dezembro de 1965. Definição dos Cursos de Pós-Graduação. Documenta, no 44 do Conselho Federal de Educação, Brasília (DF): Ministério da Educação e Cultura; 1965.

2. Brasil. CAPES. Plano Nacional de Pós-Graduação (PNPG) 2005-2010; Brasília (DF): Ministério da Educação e Cultura; 2004.

3. Brasil. Lei $n^{0}$ 9.394, de 20 de dezembro de 1996. Estabelece as Diretrizes e Bases da Educação Nacional. In: Brzesinski I, organizador. LDB Interpretada: diversos olhares se entrecruzam. São Paulo (SP): Cortez; 1997.

4. Ministério da Educação e Cultura (BR). Conselho Nacional de Educação. Resolução CNE/CES 3/2001. Diário Oficial da União, 2001 nov 9; Seção 1: 37.

5. Batista NA, Batista SHS, organizadores. A Disciplina Formação Didático-Pedagógica em Saúde na Pós-Graduação Stricto Sensu da UNIFESP/EPM: Uma Proposta em Foco. Docência em Saúde: temas e experiências. São Paulo (SP): SENAC; 2004.

6. Bardin L. Análise de conteúdo. $3^{\mathrm{a}}$ ed. Lisboa (POR): Edições 70 LTDA; 2004.

7. Imbernon F. Formação docente e profissional: formar-se para a mudança e a incerteza. $4^{\text {a }}$ ed. São Paulo (SP): Cortez; 2004.

8. Vasconcelos MLMC. Contribuindo para a formação de professores universitários: relatos de experiências. In: Masseto MT, organizador. Docência na universidade. $6^{a}$ ed. Campinas (SP): Papirus; 1998.

9. Nogueira Sotolongo M, Rivera Michelena N, Blanco Horta F. Desarrollo de competencias para la gestión docente en la educación médica superior. Rev Cubana Educ Med Super 2003; 17(3).

10. Schön $D$. Formar professores como profissionais reflexivos. In: Nóvoa A, organizador. Os professores e sua formação. Lisboa (POR): Dom Quixote; 1992. p. 77-91.

11. Faria JIL, Casagrande LDR. A educação para o século XXI e a formação do professor reflexivo na enfermagem. Rev Latino-am Enfermagem 2004; 12(5): 821-7.

12. Nóvoa A. Formação de professores e profissão docente. In Nóvoa A, organizador. Os professores e sua formação. Lisboa (POR): Dom Quixote; 1992. p. 15-33.

13. 13 Therrien J. 0 saber do trabalhador docente e a formação do professor. In: Neto AS, Maciee LSB. organizadores. Reflexões sobre a Formação de Professores. Campinas(SP):Papirus, 2002; 103-114.

14. Masetto MT. Docência universitária: repensando a aula. In: Teodoro A, Vasconcelos ML. organizadores. Ensinar e aprender no ensino superior. São Paulo (SP): Editora Mackenzie-Cortez; 2003. p. 79-108.

15. Castanho ME. Professores do ensino superior da área da saúde e sua prática pedagógica. Interface Comun Saúde Educ 2002; $6(10)$.

16. Soler Martinez $\mathrm{C}$. Reflexiones acerca del término competencias en la actividad docente. Rev Cubana Educ Med Super 2004; 18(1): 1-6.

17. Anastasiou LGC, Alves LP, organizadoras. Processos de Ensinagem na universidade - pressupostos para as estratégias de trabalho em aula. Joinville (SC): UNIVALI; 2003. 